\title{
Adenomyoma of the common bile duct: a rare lesion diagnosed and treated by ERCP
}

Benign biliary tumors are extremely rare, with an incidence ranging from $0.02 \%$ to $0.10 \%$ based on pathological examination of resected ducts [1]. Adenomyomas are defined as duct-like structures with hyperplasia of smooth muscle cells. To our knowledge, only 11 cases originating from the common bile duct have been reported to date [2]. Most of the cases have been diagnosed after extensive surgical resections. This report describes a case of an adenomyoma diagnosed and treated by an endoscopic approach.

A 50-year-old woman presented with abdominal pain and underwent an abdominal ultrasound, which showed dilatation of the common bile duct. Liver test results were all within the normal range. Magnetic resonance cholangiopancreatography was performed and revealed mild dilatation of the common bile duct, with a small filling defect on the distal portion ( $\bullet$ Fig.1a). Endoscopic ultrasound confirmed dilation of the biliary tree with a well-defined hypoechoic lesion near the papilla measuring $5.2 \mathrm{~mm}(\bullet$ Fig. 1 b).

Fine-needle aspiration was performed, but because it was challenging to maneuver the needle towards the small lesion, an endoscopic retrograde cholangiopancreatography was performed simultaneously. Access to the biliary tree was achieved via dissection of the infundibulum, as standard cannulation was not successful. Cholangiography demonstrated a filling defect near the papilla ( Fig.1 c). The endoscopic view showed a small polypoid lesion in the distal bile duct ( Fig.2a), which was resected using biopsy forceps

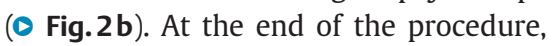
the distal bile duct was clear with no further obstruction ( $\bullet$ Fig. 2 c). Results of his- topathological analysis were compatible with a diagnosis of adenomyoma.

The patient had a satisfactory postprocedural course, and a major surgical intervention was thus avoided.

This case demonstrates the importance of combining direct visualization, diagnostic imaging, and histopathological analysis for the successful treatment of biliary lesions, as can be seen in the video (๑ Video 1).

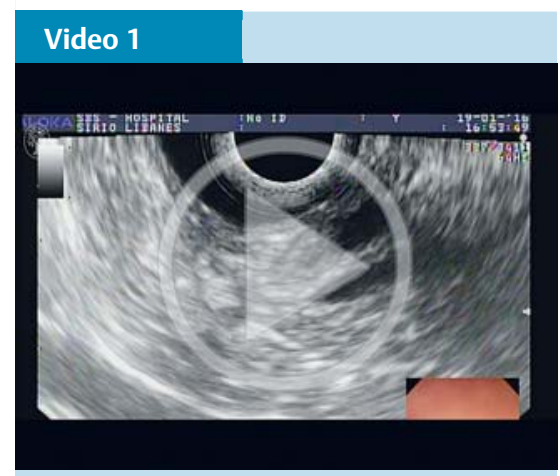

Endoscopic treatment of an adenomyoma of the common bile duct.
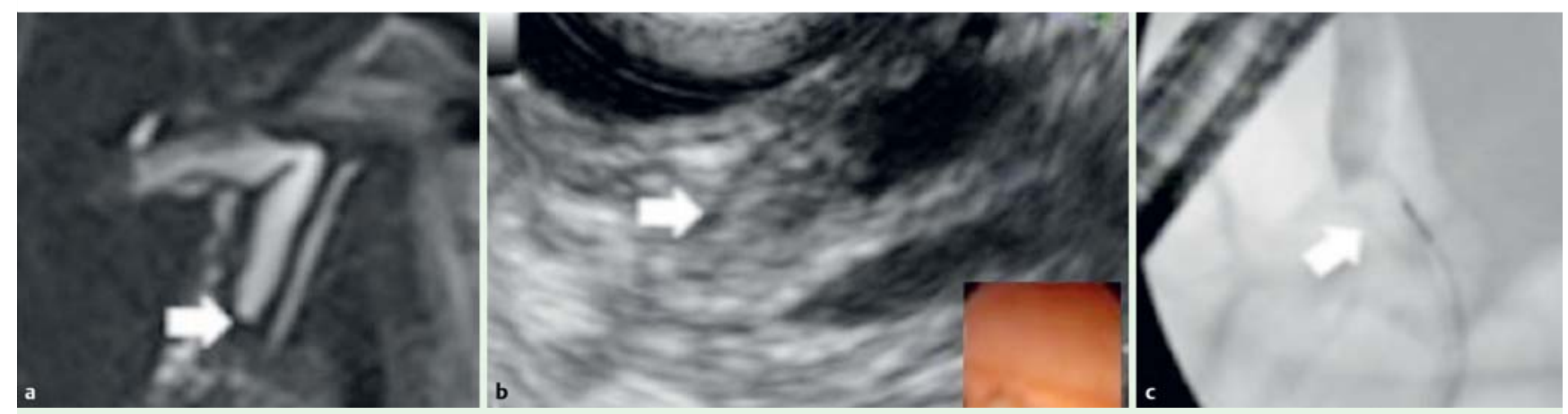

Fig. 1 Imaging studies in a patient with adenomyoma. a Magnetic resonance cholangiopancreatography showed mild dilatation of the common bile duct with a small filling defect (arrow) in the distal portion. b Endoscopic ultrasound revealed a well-defined hypoechoic lesion (arrow) near the papilla measuring $5.2 \mathrm{~mm}$. c Cholangiography demonstrated a small filling defect (arrow) near the papilla.
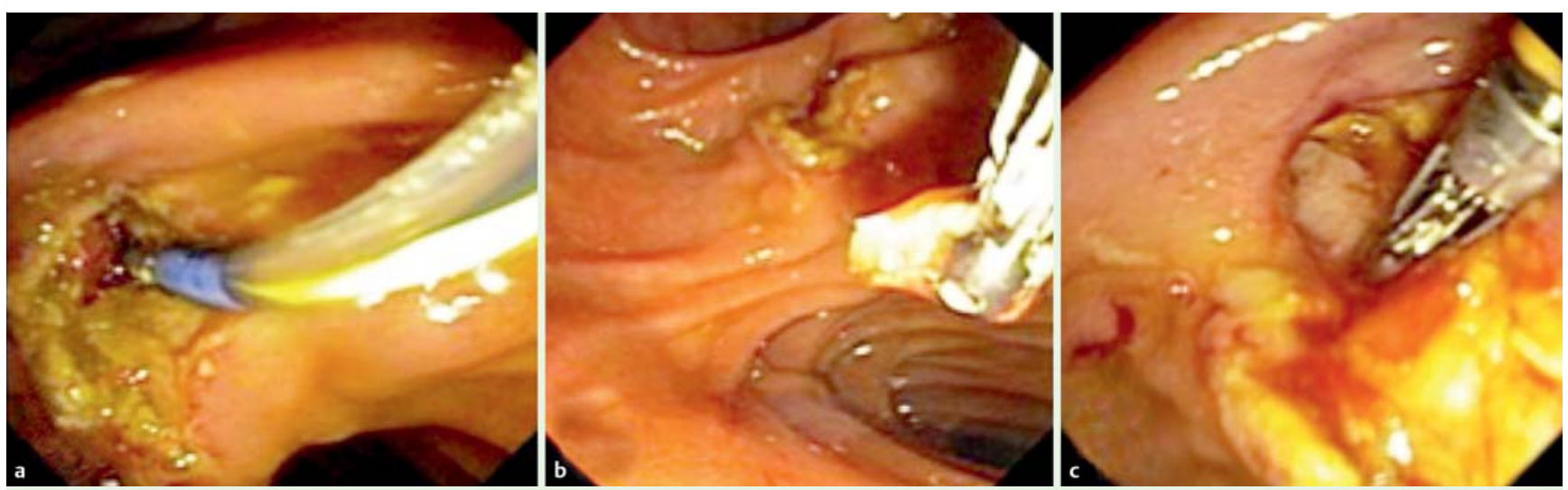

Fig. 2 Endoscopic view. a A small polypoid lesion was seen in the distal bile duct. b Resection of the lesion using biopsy forceps. $\mathbf{c}$ The unobstructed distal bile duct at the end of the procedure. 
Endoscopy_UCTN_Code_CCL_1AZ_2AC

Competing interests: None

Marco A. D’Assuncao ${ }^{1}$, Saverio T. N. Armellini ${ }^{1}$, Daniel Moribe ${ }^{1}$, Lucas S. Nova da Costa ${ }^{1}$, Gisele F. C. Leite ${ }^{1}$, Larissa M. Vendrame ${ }^{1}$, Andre L. Montagnini²

${ }^{1}$ Department of Endoscopy, Hospital Sirio Libanes, São Paulo, Brazil

2 Department of Surgery, Hospital Sirio Libanes, São Paulo, Brazil

\section{References}

1 Hai S, Yamamoto S, Tanaka H et al. Adenomyoma of the common hepatic duct mimicking bile duct cancer: report of a case. Surg Today 2007; 37: 608-611

2 Kumari N, Vij M. Adenomyoma of ampulla: a rare cause of obstructive jaundice. JSCR 2011; 8: 6

\section{Bibliography}

Dol http://dx.doi.org/

10.1055/s-0042-111312

Endoscopy 2016; 48: E266-E267

(c) Georg Thieme Verlag KG

Stuttgart · New York

ISSN 0013-726X
Corresponding author

Marco A. D'Assuncao, MD

Endoscopy Unit

Hospital Sirio Libanes

Rua Adma Jafet, $911^{\circ} \mathrm{SS}$

São Paulo, SP

01308-050

Brazil

Fax: +55-11-31553721

mada.lelo@gmail.com 